\title{
ANALISIS PENDAPATAN USAHA GULA AREN DI DUSUN KALATIN, KECAMATAN RATAHAN KABUPATEN MINAHASA TENGGARA
}

\author{
Erffelient Porobaten \\ O. Esry H. Laoh \\ Nordy F. L. Waney
}

\begin{abstract}
This study aims to see how much income earned by farmers. This study was conducted from July to September 2017. The data used are primary data and secondary data. This research was conducted by direct interview technique with 18 (eighteen) respondents in this case palm sugar processor and also using written data in document form obtained from village head of North Lowu Village. The data obtained will be analyzed using descriptive analysis and will be presented in tabular form. Total acceptance of all palm sugar processors in Kalatin Hamlet, amounting to Rp.3.310.000 / day of the total revenue obtained by all palm sugar processing with a cost incurred of Rp.2.411.902 then, obtained profit by 18 processors that is Rp.898.098 / day if not calculated raw material costs, then each processor gain profit Rp.49.898/day. However, if calculated raw material costs then the losses experienced by all palm sugar processing that is Rp.-2.903.902 / day with the cost incurred is Rp. 6.213.902 and each processor suffered loss of Rp.- 161.327 / day. If the cost for the raw material and labor were not included, the processing of palm sugar in Kalatin Hamlet is economically and feasible to be cultivated by $R / C=1,37$.
\end{abstract}

Keywords: Revenue Analysis, Palm Sugar, Kalaten Sub-Village, Ratahan Sub-District, Southeast Minahasa Regency.

\begin{abstract}
ABSTRAK
Penelitian ini bertujuan untuk melihat seberapa besar pendapatan yang diperoleh petani. Penelitian ini dilaksanakan pada bulan Juli hingga September 2017. Data yang digunakan adalah data primer dan data sekunder. Penelitian ini dilakukan dengan teknik wawancara langsung dengan 18 (delapan belas) orang responden dalam hal ini pengolah gula aren dan juga menggunakan data tertulis dalam bentuk dokumen yang diperoleh dari Kantor Kelurahan Lowu Utara. Data yang diperoleh dianalisis mengunakan analisis deskriptif dan disajikan dalam bentuk tabel. Total penerimaan seluruh pengolah gula aren di Dusun Kalatin, sebesar Rp. 3.310.000/hari. Dari jumlah penerimaan yang diperoleh seluruh pengolah gula aren dengan biaya yang dikeluarkan sebesar Rp. 2.411.902 maka, diperoleh keuntungan oleh 18 orang pengolah yaitu Rp. 898.098/hari jika tidak dihitung biaya bahan baku, maka setiap pengolah memperoleh keuntungan Rp. 49.898. Namun, jika dihitung biaya bahan baku maka kerugian yang dialami oleh seluruh pengolah gula aren yaitu sebesar Rp. - 2.903.902/hari dengan biaya yang dikeluarkan yaitu Rp. 6.213 .902 dan setiap pengolah mengalami kerugian sebesar Rp. - 161.327/hari. Bila biaya untuk bahan baku dan upah tenaga kerja dalam keluarga tidak diperhitungkan maka pengolahan gula aren di Dusun Kalatin menguntungkan secara ekonomi dan layak diusahakan ditunjukkan oleh nilai $\mathrm{R} / \mathrm{C}=1,37$.
\end{abstract}

Kata Kunci: analisis pendapatan, gula aren, Dusun Kalatin, Kecamatan Ratahan, Kabupaten Minahasa Tenggara. 


\section{PENDAHULUAN}

\section{Latar Belakang}

Tanaman aren (Arenga Pinnata Merr) merupakan tanaman yang menghasilkan bahan bahan industri karena hampir semua bagian tanaman ini dapat dimanfaatkan dan memiliki nilai ekonomi. Tanaman aren sebagian besar diusahakan oleh petani dan belum diusahakan dalam skala besar, karena pengelolaan tanaman belum menerapkan teknik budidaya yang baik menyebabkan produktivitas pertanaman rendah.

Produk utama tanaman aren adalah nira hasil penyadapan dari bunga jantan yang dijadikan gula aren maupun minuman ringan, cuka dan alkohol (Akuba, 2004; Rindengan dan Manaroinsong, 2009). Meskipun manfaat pohon aren cukup luas, namun sebagian besar masyarakat yang telah mengenyam keuntungan dari keberdaaan sumber daya hayati ini belum membudidayakannya secara baik. Sebagian masyarakat Indonesia masih mengandalkan aren yang tumbuh secara alami untuk berbagai kebutuhan (Widyawati, 2012).

Industri gula aren merupakan salah satu bentuk usaha peningkatan pendapatan penduduk dan bisa meningkatkan pendapatan asli daerah bertumpu pada ekonomi kerakyatan yang sekaligus menciptakan lapangan pekerjaan dan untuk memperoleh atau menambah pendapatan keluarga meskipun dalam proses pengolahan masih menggunakan peralatan yang sederhana atau dikerjakan secara tradisional.

Dusun Kalatin merupakan salah satu daerah yang potensial untuk usaha pengolahan gula aren di Kabupaten Minahasa Tenggara, tepatnya di Kecamatan Ratahan, Kelurahan Lowu Utara. Kegiatan produksi gula aren pada daerah ini dilakukan secara tradisional, juga didukung oleh metode pembakaran yang hanya menggunakan satu tungku pembakaran sehingga memakan waktu yang lama untuk satu kali produksi gula aren yaitu sekitar 4-6 jam. Bahan bakar yang digunakan untuk memasak gula aren yaitu menggunakan kayu bakar. Cuaca sangat berpengaruh pada kualitas dari air nira yang disadap oleh petani. Apabila musim kemarau, maka air nira yang dihasilkan sedikit namun memiliki kualitas gula aren yang baik. Saat musim hujan, air nira yang dihasilkan banyak namun kualitas gula aren yang dihasilkan kurang baik atau menjadi masam karena air nira tersebut sudah mengalami proses fermentasi. Nira yang diperoleh petani yaitu dari pohon aren milik sendiri dan untuk mengambila nira dikebun, petani menggunakan kendaraan bermotor.

Pendapatan petani dipengaruhi oleh banyak - sedikitnya nira yang diperoleh. Apabila nira yang diperoleh petani banyak, maka banyak pula gula aren yang akan dihasilkan. Bahan bakar yang digunakan petani berupa kayu bakar, diperoleh dengan menyewa satu orang tenaga kerja untuk mencarinya.Gula aren dari Dusun Kalatin memiliki peluang pasar yang sangat prospektif karena berbahan dasar organik dan terjamin kebersihannya.

\section{Deskripsi Tanaman Aren}

Pohon aren adalah pohon yang berdiri tegak dan tinggi, berbatang bulat warna hijau kecokelatan, bentuk daun menyirip berwarna hijau tua, bunga terdiri atas bunga jantan yang menyatu dalam satu tongkol ukuran panjang 1$1,2 \mathrm{~cm}$. Bunga betina pada tongkol yang lain bentuk bulat yang terdiri atas bakal buah tiga buah dan berwarna kuning keputihan (Effendi, 2010). Biji pada buah aren muda mengandung kristal Ca-oksalat, yang bila menyentuh kulit dapat menyebabkan iritasi dan menimbulkan rasa gatal. Aren mulai berbunga, kira-kira setelah tanaman berumur 7-10 tahun. Tangkai malai bunga dapat disadap setiap hari, selama 2-3 bulan, menghasilkan 10-30 liter nira tiap hari. Kondisi penyadapan terbaik pada umur 8-9 tahun saat mayang bunga sudah keluar. Penyadapan dapat dilakukan pagi dan sore, setiap tahun dapat disadap 3-12 tangkai bunga dengan hasil rata-rata 6,7 liter/hari atau sekitar 900-1600 liter/pohon/tahun.

Tanaman aren dapat tumbuh dengan baik di dekat pantai sampai pada dataran tinggi 1200 $\mathrm{m}$ dari permukaan laut.Pertumbuhan tanaman ini membutuhkan kisaran suhu $20-25^{\circ} \mathrm{C}$, terutama untuk mendorong perkembangan generatif agar dapat berbunga dan berbuah. Kelembaban tanah dan ketersediaan air sangat diperlukan saat proses pembentukan mahkota tanaman, dimana curah hujan yang dibutuhkan antara 1200-3500 mm/tahun agar kelembaban tanah dapat dipertahankan (Effendi, 2009). 


\section{Konsep Penerimaan}

Penerimaan adalah hasil pengurangan antara hasil penjualan dengan semua biaya yang dikeluarkan (Mubyarto, 1991).

$$
\begin{aligned}
& \mathrm{TR}=\mathrm{Y} \times \mathrm{P} \\
& \text { dimana : }
\end{aligned}
$$

$$
\begin{aligned}
\mathrm{TR}= & \text { Total Revenue }(\text { Total Penerimaan) } \\
\mathrm{Y}= & \text { Produksi yang diperoleh dalam } \\
& \text { usahatani } \\
\mathrm{P}= & \text { Harga Jual }
\end{aligned}
$$

\section{Konsep Pendapatan}

Soekartawi (1995), pendapatan usaha tani adalah selisih antara penerimaan dengan semua biaya atau dapat ditulis dengan sistematis sebagai berikut :

$\mathrm{I}=\mathrm{TR}-\mathrm{TC}$

Dimana :

$$
\begin{aligned}
\mathrm{I} & =\text { income } \\
\mathrm{TR} & =\text { Total Revenue }(\text { penerimaan) } \\
\mathrm{TC} & =\text { Total Cost }
\end{aligned}
$$

\section{Konsep Analisis Return Cost Ratio (R/C)}

Menurut Soekartawi (1995), untuk mengetahui apakah usahatani yang dilaksanakan oleh petani mengalami keuntungan atau kerugian, maka diperlukan analisis $\mathrm{R} / \mathrm{C}$ yang merupakan perbandingan antara penerimaan dan biaya.

$\mathrm{a}=\mathrm{R} / \mathrm{C}$

dimana :

$\mathrm{a}=$ Perbandingan Antara Penerimaan dan

Biaya

$\mathrm{R}=$ Revenue (Penerimaan)

$\mathrm{C}=\operatorname{Cost}$ (Biaya)

Apabila :

$\mathrm{R} / \mathrm{C}<1=$ Berarti usahatani mengalami kerugian

$\mathrm{R} / \mathrm{C}=1=$ Berarti usahatani tidak menguntungkan dan tidak merugikan

$\mathrm{R} / \mathrm{C}>1=$ Berarti usahatani menerima Keuntungan.

\section{Rumusan Masalah}

1. Berapa besar biaya yang dikeluarkan petani dari proses produksi sampai menjadi gula aren?

2. Berapa pendapatan yang diperoleh petani dalam usaha mengolah nira menjadi gula aren ?

\section{Tujuan dan Manfaat Penelitian}

Tujuan penelitian ini yaitu :

1. Untuk mengetahui besarnya biaya yang dikeluarkan petani selama proses produksi gula aren.

2. Untuk mengetahui pendapatan yang diperoleh dari mengolah nira menjadi gula aren di Dusun Kalatin.

Manfaat dari penelitian ini diharapkan dapat memberikan informasi bagi pertani dan masukan bagi pihak-pihak yang membutuhkan informasi.

\section{METODOLOGI PENELITIAN}

\section{Tempat dan Waktu Pelaksanaan}

Penelitian ini dilakukan di Dusun Kalatin, Kecamatan Ratahan dan penelitian ini dilaksanakan selama 3 (Tiga) bulan mulai dari persiapan, pengolahan data sampai pembuatan laporan.

\section{Metode Pengumpulan Data}

Adapun responden dalam penelitian ini adalah semua pengolah gula aren di daerah penelitian yaitu sebanyak 18 orang.Data yang digunakan dalam penelitian ini adalah data primer dan sekunder. Data primer diperoleh dari hasil wawancara langsung dengan petani gula aren dengan menggunakan kuesioner yang telah dipersiapkan terlebih dahulu, sedangkan data sekunder diperoleh dari Balai Penelitian Palma dan instansi lain.

\section{Metode Pengambilan Sampel}

Objek dalam penelitian ini adalah masyarakat Desa Nain yang mengusahakan jajanan kue. Pengusaha jajanan kue yang berada di Desa Nain berjumlah 48 pengusaha. Namun dari 48 pengusaha jajanan kue ini terdapat 15 pengusaha yang secara rutin membuat dan menjual kue sedangkan 33 pengusaha lainnya hanya membuat kue berdasarkan pesanan atau ketersediaan modal. Pengambilan sampel dalam penelitian ini dilakukan secara sengaja (purposive sampling), yaitu hanya 15 pengusaha jajanan kue yang secara rutin menproduksi dan menjual kue. 


\section{Konsep dan Pengukuran Variabel}

Variabel yang akan diukur dalam penelitian ini adalah :

1. Tenaga kerja : Jumlah tenaga kerja dalam keluarga dan luar keluarga yang terlibat dalam proses produksi gula aren (mulai panen sampai jadi gula).

2. Bahan Baku : Nira aren yang digunakan dalam pembuatan gula aren dihitung tiap kali penyadapan.

3. Biaya Transportasi : Biaya yang dikeluarkan petani dalam penggunaan kendaraan bermotor untuk kegiatan transportasi berupa pembelian bensin (Rp/hari).

4. Biaya Produksi (Rp) : Jumlah biaya yang dikeluarkan untuk memproduksi gula aren 1 kali produksi .

5. Harga Jual : Harga jual gula aren ditingkat petani $(\mathrm{Rp} / \mathrm{kg})$.

6. Tingkat Keuntungan : Penerimaan dikurangi biaya-biaya per 1 kali proses produksi.

\section{Analisis Data}

Analisis yang digunakan dalam penelitian ini adalah analisis deskriptif dan disajikan dalam bentuk tabel. Sedangkan untuk mengetahui keuntungan gula aren menggunakan analisis keuntungan usaha (Wilson dalam Wua 2009).

Untuk mengetahui besarnya biaya penyusutan alat yang digunakan perhitungan

$\mathrm{P}=\mathrm{HA}-\mathrm{HBT}$

Keterangan :

$\mathrm{P}=$ Biaya penyusutan

HA $=$ Harga awal

HB = Harga akhir

$\mathrm{T}=$ Umur ekonomis alat

Untuk mengetahui tingkat keuntungan usaha dapat diperoleh dengan perhitungan:

$\mathrm{P}=\mathrm{TR}-\mathrm{TC}$

Keterangan:

$\mathrm{P}=$ Profit/Keuntungan

$\mathrm{TR}=$ Total Revenue/Total Penerimaan

$\mathrm{TC}=$ Total Cost $/$ Total biaya produksi

Untuk mengetahui apakah usahatani yang dilaksanakan oleh petani mengalami keuntungan atau kerugian, maka diperlukan analisis $\mathrm{R} / \mathrm{C}$ yang merupakan perbandingan antara penerimaan dan biaya.

$\mathrm{a}=\mathrm{R} / \mathrm{C}$

Keterangan :

$\mathrm{a}=$ Perbandingan antara penerimaan dan biaya

$\mathrm{R}=$ Revenue (penerimaan)

$\mathrm{C}=$ Cost (biaya)

Apabila :

$\mathrm{R} / \mathrm{C}<1$ = berarti usahatani tidak mengalami keuntungan

$\mathrm{R} / \mathrm{C}=1=$ berarti usahatani tidak menguntungan dan tidak merugikan

$\mathrm{R} / \mathrm{C}>1=$ berarti usahatani menerima keuntungan.

\section{HASIL DAN PEMBAHASAN}

\section{Deskripsi Daerah Penelitian}

Kalatin merupakan sebuah dusun yang berada di wilayah administrasi Lowu Utara, Kecamatan Ratahan Kabupaten Minahasa Tenggara. Berbentuk dusun karena pemukimannya terpisah jauh yaitu sekitar 2,1 $\mathrm{km}$ dengan pemukiman kelurahan induk. Letak dusun kalatin berbatasan dengan kawasan hutan lindung. Namun Dusun Kalatin sudah keluar dari peta hutan lindung.

Dengan batas - batas wilayah Dusun Kalatin adalah sebagai berikut :

1. Sebelah Utara berbatasan dengan Kepolisian Pangu

2. Sebelah Timur berbatasan dengan Perkebungan Pangu

3. Sebelah Selatan berbatasan dengan Perkebunan Rangkuli

4. Sebelah Barat berbatasan dengan Wilayah Soputan

Dusun Kalatin mempunyai iklim kemarau dan penghujan, ketinggian Dusun Kalatin kurang lebih $3.500 \mathrm{mdl}$, suhu udara tergolong dingin. Luas wilayah keseluruhan Dusun Kalatin adalah 550 ha dengan pembagian cakupan wilayah untuk lahan pemukiman 22 ha, lahan pertanian 350 ha, lahan pekuburan 0,75 ha dan hutan lindung 177,25 ha.

\section{Keadaan Penduduk}

Data Penduduk Dusun Kalatin menunjukan pada tahun 2016 memiliki jumlah penduduk sebanyak 397 jiwa. Jumlah penduduk 
laki-laki 212 jiwa dan perempuan 185 jiwa. Jumlah KK 119 jiwa. Tabel 1 menunjukan jumlah penduduk menurut laki-laki dan perempuan.

\begin{tabular}{|c|c|c|c|}
\hline Tabel & $\begin{array}{l}\text { 1. Jumlah Penduduk } \\
\text { Didusun Kalatin }\end{array}$ & Menurut & Jenis Kelamin \\
\hline No. & $\begin{array}{l}\text { Jenis Kelamin } \\
\text { (Orang) }\end{array}$ & $\begin{array}{c}\text { Jumlah } \\
\text { Penduduk }\end{array}$ & $\begin{array}{c}\text { Persentase } \\
(\%)\end{array}$ \\
\hline 1. & Laki - Laki & 212 & 53 \\
\hline 2. & Perempuan & 185 & 47 \\
\hline & Jumlah & 397 & 100 \\
\hline
\end{tabular}

Sumber : Kantor Desa Lowu Utara 2016

Berdasarkan Tabel 1, dapat dilihat bahwa jumlah penduduk berjenis kelamin perempuan sebanyak 185 jiwa atau $(47 \%)$ dan jumlah penduduk berjenis kelamin laki-laki sebanyak 212 jiwa atau (53\%). Bila dihitung menurut Rasio Jenis Kelamin, RJK 115 (>100) jumlah penduduk laki-laki lebih banyak dibandingkan dengan jumlah penduduk perempuan, oleh karena itu potensi pertumbuhan penduduk secara alami di Dusun Kalatin menjadi lambat. Beda jika RJK < 100 jumlah penduduk perempuan lebih banyak dibandingkan dengan jumlah penduduk laki-laki maka potensi pertumbuhan penduduk secara alami juga akan sangat cepat. Karena jika jumlah penduduk perempuan lebih banyak dan jumlah penduduk laki-laki lebih sedikit maka, penduduk perempuan dapat menikah dengan laki-laki yang dari luar daerah.

\section{Karakteristik Responden}

\section{Umur Responden}

Umur dapat mempengaruhi kemampuan seseorang untuk bekerja secara fisik. Umur juga dapat mempengaruhi produktivitas kerja dan peranannya dalam pengambilan keputusan dari berbagai alternatif pekerjaan yang dilakukan. Umur produktif antar 15 hingga 55 tahun. Jumlah responden disajikan pada Tabel 2.

Tabel 2. Jumlah Responden Menurut Kelompok Umur

\begin{tabular}{lccc}
\hline No. & $\begin{array}{c}\text { Umur } \\
\text { (Tahun) }\end{array}$ & $\begin{array}{c}\text { Jumlah Responden } \\
\text { (Orang) }\end{array}$ & $\begin{array}{c}\text { Persentase } \\
(\boldsymbol{\%})\end{array}$ \\
\hline 1. & $30-39$ & 5 & 28 \\
2. & $40-49$ & 8 & 44 \\
3. & $50-62$ & 5 & 28 \\
\hline Jumlah & 18 & 100 \\
\hline \multicolumn{4}{l}{ Sumber : Diolah dari data primer 2017}
\end{tabular}

Tabel 2, menunjukan bahwa sebagian besar pengolah gula aren berada pada umur 40-
49 tahun yaitu sebanyak 8 orang atau (44\%) dari total responden. Diikuti umur 30 - 39 tahun yaitu sebanyak 5 orang atau (28\%) dan umur 50 - 62 tahun yaitu sebanyak 5 orang atau (28\%). Responden yang berumur 50 - 62 tahun masih aktif mengolah gula aren karena, selain untuk memenuhi kebutuhan hidup juga sedang menyekolahkan anak baik dari tingkat SD maupun sampai perguruan tinggi. Meskipun usia dari pengolah gula aren ini sudah lanjut tapi gula aren yang mereka hasilkan tetap memiliki kualitas gula yang baik.

\section{Tingkat Pendidikan Responden}

Pendidikan sangat berperan penting dalam menciptakan perubahan dalam kehidupan masyarakat. Pendidikan dijadikan sebagai salah satu faktor yang menentukan produktifitas kerja, sikap serta kemampuan seseorang dalam berfikir dan bertindak. Tingkat pendidikan formal responden rata-rata adalah Sekolah Dasar (SD).

Mengolah nira aren menjadi gula tidak memerlukan pendidikan formal yang tinggi, ini terbukti dari pendidikan rata - rata responden yang hanya sampai pada tingkat SD. Ketrampilan mereka diperoleh dari pengalaman yang setelah sekian tahun mengolah gula aren. Oleh karena tingkat pendidikan responden yang hanya sampai Sekolah Dasar (SD) maka, menjadi kesempatan dari pengumpul untuk memperoleh keuntungan yang besar. Namun, jika responden ingin menjadi pengusaha gula aren pendidikan formal mempengaruhi, karena untuk menjadi pengusaha mereka akan terus berusaha bagaimana caranya agar gula aren yang dihasilkan layak dipasarkan dimana saja dan mendapat harga pasaran yang dapat menguntungkan.

\section{Jumlah Tanggungan Keluarga Responden}

Jumlah anggota keluarga yang terhitung dalam jumlah tanggungan umumnya membantu keluarga dalam hal penyediaan tenaga kerja dalam keluarga dengan sendirinya akan mengurangi masuknya tenaga kerja dari luar keluarga. Sehingga pengolah juga tidak perlu mengeluarkan biaya untuk meyewa tenaga kerja dalam membantu proses produksi gula aren.

Tabel 3, menunjukan jumlah tanggungan keluarga responden terbanyak 3 orang yaitu 11 orang responden atau (61\%), dan jumlah 
tanggungan keluarga responden paling sedikit sebanyak 5 orang yaitu 1 orang responden atau $(5 \%)$. Berdasarkan hasil penelitian ada beberapa orang istri dari pengolah gula aren yang membantu proses produksi gula aren, misalnya mengambil air dan mencuci tempurung yang menjadi tempat untuk mencetak gula aren dan membantu menjemur kayu api yang sudah dipotong oleh pengolah agar jika kayu api sudah habis ada persediaan kayu api yang kering untuk memasak gula aren.

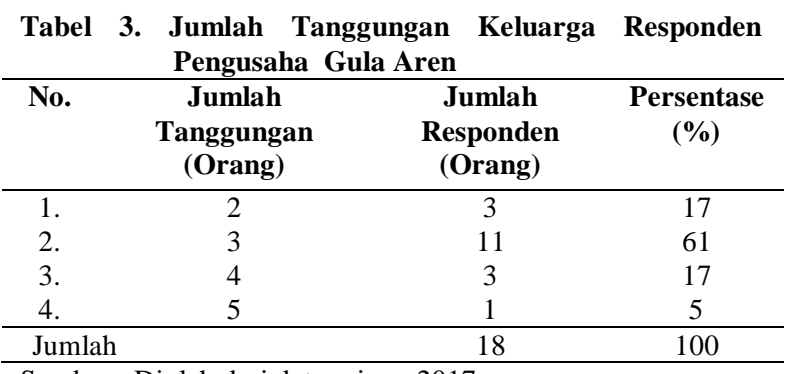

Sumber : Diolah dari data primer 2017

\section{Jumlah Pohon Yang Disadap}

Jumlah pohon yang disadap oleh pengolah saat ini sangat menentukan banyak sedikitnya hasil produksi gula aren. Banyak pohon yang disadap maka banyak pula hasil dari nira aren namun jika sedikit pohon yang disadap maka sedikit pula nira aren yang dihasilkan.

Tabel 4. Jumlah Pohon Yang Disadap Responden

\begin{tabular}{cccc} 
Pengolah Gula Aren & \\
\hline No. & $\begin{array}{c}\text { Jumlah } \\
\text { Pohon } \\
\text { (Batang) }\end{array}$ & $\begin{array}{c}\text { Jumlah } \\
\text { Responden } \\
\text { (Orang) }\end{array}$ & $\begin{array}{c}\text { Persentase } \\
(\boldsymbol{\%})\end{array}$ \\
\hline 1. & $4-6$ & 5 & 28 \\
2. & $7-8$ & 5 & 28 \\
3. & 10 & 8 & 44 \\
\hline & Jumlah & 18 & 100 \\
\hline
\end{tabular}

Sumber : Diolah dari data primer 2017

Tabel 4, menunjukan bahwa dari 18 orang responden pengolah gula aren, jumlah pohon yang disadap pengolah terbanyak adalah 8 orang responden yaitu 10 pohon atau (44\%). Sedangkan jumlah pohonnya sama adalah 5 orang responden yaitu 4-6 pohon atau (28\%) dan 5 orang responden yaitu 7-8 pohon atau (28\%). Jumlah pohon yang paling sedikit yaitu 4-6 pohon dikarenakan ada pohon yang sudah tidak dapat disadap lagi (mati). Saat ini para pengolah sedang membuka mayang baru, 1 pohon aren yang berukuran besar dapat menghasilkan 5-20 mayang, namun tidak semua mayang dapat dibuka. Dalam 1 pohon aren hanya bisa dibuka sebanyak 5 mayang, dan mayang yang dapat bertahan untuk disadap dalam jangka waktu lama adalah mayang jantan. Pohon yang berukuran kecil hanya menghasilkan 3-10 mayang dan 1 mayang dapat disadap 2-4 bulan lamanya tergantung pada banyak sedikitnya air nira yang keluar. Sesudah itu pengolah akan membuka lagi mayang baru untuk menggantikan mayang yang sudah mati dan jika semua mayang sudah dibuka dan tidak menghasilkan nira aren lagi, maka pohon tersebut akan mati.

\section{Pengalaman Mengolah Gula Aren}

Pengalaman berusaha yang dimiliki responden akan erat kaitannya dengan cara menentukan langkah-langkah dalam melakukan tindakan pengelolaan usahanya dan juga akan lebih efisien dalam mengerjakan usaha pengolahan gula aren.

Tabel 5. Pengalaman Responden Pengolah Gula Aren

\begin{tabular}{cccc}
\hline No. & $\begin{array}{c}\text { Pengalaman } \\
\text { Berusaha } \\
\text { (Tahun) }\end{array}$ & $\begin{array}{c}\text { Jumlah } \\
\text { Responden } \\
\text { (Orang) }\end{array}$ & $\begin{array}{c}\text { Persentase } \\
\mathbf{( \% )}\end{array}$ \\
\hline 1. & $<3$ & 9 & 50 \\
2. & $5-10$ & 5 & 28 \\
3. & $20-35$ & 4 & 22 \\
\hline & Jumlah & 18 & 100 \\
\hline
\end{tabular}

Sumber : Diolah dari data primer 2017

Tabel 5, menunjukan jumlah pengalaman responden terbanyak adalah 7 bulan sampai dengan 3 tahun yaitu (50\%) sedangkan jumlah pengalaman paling sedikit adalah 20 sampai 35 tahun yaitu (22\%). Pada dasarnya semua responden pengolah gula aren ini sudah sejak lama mengolah gula aren, namun karena ada fluktuasi harga yang mempengaruhi proses produksi mereka sehingga apabila harga gula aren turun mereka berhenti mengolah gula aren dan mencari pekerjaan lain dan jika harga gula aren naik mereka kembali mengolah gula aren. Semakin lama pengalaman mengolah gula aren maka, semakin baik pula kualitas gula aren yang dihasilkan ini terbukti dari pengalaman pengolah yang sudah 5 tahun ke atas mengolah gula aren, mereka sangat 
jarang menghasilkan gula yang kurang baik (gula tare). Yang disajikan pada tabel diatas adalah mereka yang aktif mengolah gula aren saat ini.

\section{Peralatan Pendukung Produksi Gula Aren}

Peralatan untuk membuat gula aren pada dasarnya masih menggunakan peralatan sederhana yang minim digunakan yaitu berupa wajan, selangka, galon 25 ltr, galon 10 ltr, galon 5 liter, parang, pisau, terpal, tali nilon, tali plastik. Pengadaan alat pendukung yang telah diuraikan, maka pengolah harus mengeluarkan biaya tetap berupa biaya penyusutan alat, yaitu komponen biaya yang secara tidak langsung dikeluarkan pengolah untuk setiap bulan produksi, dalam hal ini pemakaian alat-alat pendukung dalam kegiatan usaha pengolahan.

Tabel 6. Rincian Biaya Penyusutan Alat Produksi Usaha Gula

\begin{tabular}{lcccc} 
Aren & $\begin{array}{c}\text { Harga } \\
\text { Awal } \\
\text { (Rp) }\end{array}$ & $\begin{array}{c}\text { Harga } \\
\text { Akhir } \\
(\mathbf{R p})\end{array}$ & $\begin{array}{c}\text { Umur } \\
\text { Ekonomis } \\
\text { (Bulan/ } \\
\text { Tahun) }\end{array}$ & $\begin{array}{c}\text { Biaya } \\
\text { Penyusutan } \\
\text { (Rp) }\end{array}$ \\
\hline Wajan & 500.000 & 0 & $60 / 5$ & 274 \\
Selangka & 150.000 & 0 & $12 / 1$ & 411 \\
Parang & 200.000 & 0 & $36 / 3$ & 183 \\
Pisau & 150.000 & 0 & $12 / 1$ & 411 \\
Galon 25 ltr & 50.000 & 0 & $12 / 1$ & 137 \\
Galon 10 ltr & 20.000 & 0 & $12 / 1$ & 55 \\
Galon 5 ltr & 10.000 & 0 & $12 / 1$ & 27 \\
Terpal & 125.000 & 0 & $6 / 0$ & 685 \\
Tali Nilon & 55.000 & 0 & $12 / 1$ & 137 \\
Tali Plastik & 15.000 & 0 & $2 / 0$ & 246 \\
\hline \multicolumn{5}{c}{ Jumlah } \\
Sumber : Diolah dari data primer 2017
\end{tabular}

Tabel 6, Menunjukan bahwa biaya penyusutan alat yang dikeluarkan setiap pengolah gula aren yaitu sebesar Rp.2.566/hari. Rata-rata atau biaya penyusutan alat yang dikeluarkan oleh pengolah gula aren adalah Rp.46.188/hari.

\section{Bahan Baku Pembuatan Gula Aren}

Ketersediaan bahan baku merupakan faktor yang paling penting untuk menentukan kelangsungan proses produksi. Bahan baku yang digunakan dalam pembuatan gula aren adalah air nira yang diambil oleh pengolah gula aren di perkebunan yang ada di tempat produksi gula aren. Sedangkan minyak kelapa, pengolah hanya membeli diwarung. Saguer (nira aren) yang diambil dari tanaman pohon aren, setiap kali pembuatan petani mengeluarkan 2-4 jerigen saguer (nira aren). Pohon aren di Dusun Kalatin tumbuh secara liar, dan beberapa ada yang ditanam sebagai tanaman pembatas tanah milik masyarakat. Dalam penelitian ini rata-rata pengolah gula aren menggunakan air nira/saguer di ambil dari pohon aren milik sendiri atau milik keluarga, agar pengolah tidak mengeluarkan biaya bahan baku untuk membeli air nira/saguer. Jika dilihat bahwa harga jual "saguer" (nira aren) di Dusun Kalatin yaitu Rp.1.600-2.000/liter. Tabel 7 menunjukan jumlah bahan baku "saguer" (nira aren) yang digunakan oleh pengolah gula aren.

Tabel 7. Jumlah Responden Pengolah Gula Aren Berdasarkan

\begin{tabular}{cccc}
\multicolumn{4}{c}{ Jumlah Bahan Baku Nira Yang Digunakan } \\
\hline $\begin{array}{c}\text { Jumlah } \\
\text { Responden }\end{array}$ & $\begin{array}{c}\text { Bahan } \\
\text { Baku Nira } \\
\text { (liter) }\end{array}$ & $\begin{array}{c}\text { Harga Jual } \\
\text { Nira/Saguer } \\
\text { (Rp/liter) }\end{array}$ & $\begin{array}{c}\text { Total Biaya } \\
\text { Bahan Baku } \\
\text { Nira }\end{array}$ \\
\hline 1 & 165 & 1.600 & 264.000 \\
2 & 300 & 1.600 & 480.000 \\
3 & 175 & 1.600 & 280.000 \\
4 & 140 & 2.000 & 280.000 \\
5 & 95 & 1.600 & 152.000 \\
6 & 75 & 1.600 & 120.000 \\
7 & 105 & 1.600 & 168.000 \\
8 & 75 & 2.000 & 150.000 \\
9 & 150 & 1.600 & 240.000 \\
10 & 105 & 2.000 & 210.000 \\
11 & 110 & 1.600 & 176.000 \\
12 & 145 & 2.000 & 290.000 \\
13 & 60 & 1.600 & 96.000 \\
14 & 135 & 2.000 & 270.000 \\
15 & 105 & 2.000 & 210.000 \\
16 & 85 & 1.600 & 136.000 \\
17 & 75 & 1.600 & 120.000 \\
18 & 100 & 1.600 & 160.000 \\
\hline Jumlah & & & 3.802 .000 \\
\hline Sumber : Diolah dari data primer 2017 &
\end{tabular}

Tabel 7, menunjukan bahwa jumlah bahan baku yang diolah oleh pengolah gula aren yaitu sebanyak 60-300 liter/hari dan jumlah biaya bahan baku nira rata-rata yang digunakan dalam pembuatan gula aren seharga Rp.1.6002.000/liter, atau total rata-rata sebesar Rp.3.802.000. Gula aren yang dihasilkan oleh para pengolah ini mempunyai dua rasa gula yaitu gula yang manis dan gula yang tidak terlalu manis. Gula aren yang manis dikarenakan pengolah mengambil air nira aren tepat pada waktu yang sudah ditentukan. Gula yang tidak terlalu manis disebabkan oleh dua faktor yaitu pertama pengolah mengambil nira aren melebihi batas waktu yang ditentukan oleh karena itu nira aren sudah mengalami proses 
fermentasi dan menjadi masam, yang kedua yaitu faktor cuaca sangat mempengaruhi apabila musim hujan kualitas nira aren menjadi kurang baik karena nira aren yang disadap sudah tercampur dengan air hujan. Wajan yang di gunakan oleh pengolah berukuran 28-34 dengan kapasitas nira 50-300 liter untuk sekali proses pemasakan gula aren.

\section{Tenaga Kerja \\ Tenaga kerja merupakan faktor} pendukung berlangsungnya usaha gula aren. Berdasarkan hasil penelitian, tenaga kerja yang digunakan oleh para pengolah dalam mengolah gula aren yaitu menggunakan tenaga pengolah itu sendiri atau tenaga kerja dalam keluarga namun, tetap akan dihitung biaya sewa tenaga kerja berdasarkan tenaga yang mereka keluarkan yaitu Rp.100.000/hari mulai dari mengambil nira sampai dengan menjadi gula aren.

\section{Bahan Bakar}

Jenis bahan bakar yang digunakan oleh pengolah dalam proses pemasakan gula aren adalah kayu bakar. Kayu bakar yang digunakan pengolah biasanya diperoleh dengan mencari dihutan ataupun dengan menyewa tenaga kerja. Berdasarkan hasil penelitian ada 14 orang pengolah yang mencari kayu bakar dibantu oleh anak maupun istri mereka untuk meringankan pekerjaan dari para pengolah. Namun, akan dihitung biaya sewa tenaga kerja berdasarkan tenaga yang mereka keluarkan. Adapula 4 orang pengolah yang menyewa 1 orang tenaga kerja (tenaga kerja luar keluarga) untuk mencari kayu bakar dan biaya sewa berkisar Rp.150.000 dengan pemakaian 1 minggu.

\section{Transportasi \\ Pengolah dalam memudahkan} mengambil nira dikebun, menggunakan kendaraan bermotor untuk kegiatan transportasi. Ada pula beberapa pengolah yang tidak mempunyai kendaraan bermotor atau pun jalan kekebun tidak bisa dilalui kendaraan bermotor maka, mereka berjalan kaki untuk mengambil nira dikebun. Penelitian ini menunjukkan bahwa ada 12 orang pengolah yang hanya berjalan kaki kekebun dan 6 orang pengolah yang membawa kendaraan bermotor. Setiap produksi pengolah gula aren yang mengeluarkan biaya transportasi berupa pembelian bensin sebesar Rp.10.000/hari.

\section{Biaya Produksi Usaha Gula Aren}

Biaya produksi merupakan keseluruhan biaya yang digunakan untuk membiayai keseluruhan proses usaha tersebut. Biaya produksi untuk mengolah gula aren terdiri dari biaya variabel (Variable Cost) dan biaya tetap (Fixed Cost). Penelitian ini menunjukan bahwa dalam kegiatan produksi gula aren, pengusaha mengeluarkan beberapa biaya untuk menunjang kegiatan produksi yaitu biaya tetap berupa biaya penyusutan alat, dan biaya variabel berupa biaya transportasi (pembelian bensin). Untuk pengadaan bahan bakar berupa kayu bakar pengolah tidak mengeluarkan biaya. Biaya bahan baku "saguer" (nira aren) pengolah gula aren di Dusun Kalatin sama sekali tidak mengeluarkan biaya dikarenakan "saguer" (nira aren) yang digunakan oleh pengolah adalah milik sendiri atau hasil dari penyadapan pohon aren milik pengolah gula aren.

Menghitung biaya produksi yang dikeluarkan pengolah gula aren menggunakan dua tabel yaitu menggunakan biaya bahan baku dan tidak menggunakan biaya bahan baku. Tabel 8 menunjukan rekapitulasi ratarata biaya produksi yang dikeluarkan oleh pengolah gula aren jika dihitung biaya bahan baku dan yang diperhitungkan biaya bahan baku.

Tabel 8. Rincian Rata-Rata Biaya Produksi Yang Dikeluarkan Petani Usaha Gula Aren

\begin{tabular}{clcc}
\hline No. & \multicolumn{1}{c}{ Uraian } & $\begin{array}{c}\text { Tidak } \\
\text { Dihitung } \\
\text { Biaya } \\
\text { Bahan } \\
\text { Baku (Rp) }\end{array}$ & $\begin{array}{c}\text { Dihitung } \\
\text { Biaya } \\
\text { Bahan } \\
\text { Baku (Rp) }\end{array}$ \\
\hline 1. & $\begin{array}{l}\text { Penyusutan } \\
\text { alat }\end{array}$ & 46.188 & 46.188 \\
2. & Bahan Baku & - & 3.802 .000 \\
3. & Transportasi & 180.000 & 180.000 \\
4. & $\begin{array}{l}\text { Tenaga } \\
\text { Kerja dk }\end{array}$ & 1.800 .000 & 1.800 .000 \\
5. & $\begin{array}{l}\text { Tenaga } \\
\text { Kerja lk }\end{array}$ & 385.714 & 385.714 \\
\hline & Jumlah & 2.411 .902 & 6.213 .902 \\
\hline
\end{tabular}

Sumber : Diolah dari data primer 2017 
Tabel 8, menunjukan bahwa biaya produksi usaha gula aren jika dihitung dengan bahan baku jumlahnya akan lebih besar yaitu Rp.6.213.902 dibandingkan jika tidak dihitung dengan bahan baku jumlahnya akan jauh lebih kecil yaitu Rp.2.411.902.

\section{Tingkat Produktivitas Dan Harga Jual Gula Aren}

Hasil produksi gula aren di Dusun Kalatin mulai dari Rp. 105.000-450.000 atau pengolah dapat memproduksi 15-30/buah setiap harinya. Harga jual yang ditawarkan bervariasi yaitu mulai dengan harga Rp.7.000-9.000/buah. Tabel 9 menunjukan tingkat produktivitas dan harga jual gula aren.

\begin{tabular}{cccc}
\multicolumn{5}{c}{ Tabel 9. Produktivitas Harga Jual Gula Aren } \\
\hline $\begin{array}{c}\text { Jumlah } \\
\text { Responden }\end{array}$ & $\begin{array}{c}\text { Rata-Rata } \\
\text { Produksi/Buah }\end{array}$ & $\begin{array}{c}\text { Harga Jual } \\
(\mathrm{Rp})\end{array}$ & $\begin{array}{c}\text { Penerimaan } \\
(\mathrm{Rp})\end{array}$ \\
\hline 1 & 35 & 9.000 & 315.000 \\
2 & 50 & 9.000 & 450.000 \\
3 & 30 & 8.000 & 240.000 \\
4 & 25 & 8.000 & 200.000 \\
5 & 20 & 7.000 & 140.000 \\
6 & 15 & 7.000 & 105.000 \\
7 & 20 & 7.000 & 140.000 \\
8 & 15 & 8.000 & 120.000 \\
9 & 30 & 7.000 & 210.000 \\
10 & 20 & 7.000 & 140.000 \\
11 & 30 & 8.000 & 240.000 \\
12 & 25 & 7.000 & 175.000 \\
13 & 15 & 7.000 & 105.000 \\
14 & 25 & 8.000 & 200.000 \\
15 & 20 & 8.000 & 160.000 \\
16 & 15 & 7.000 & 105.000 \\
17 & 15 & 7.000 & 105.000 \\
18 & 20 & 8.000 & 160.000 \\
\hline Jumlah & & & 3.310 .000 \\
\hline Sumber $:$ Diolah dari data primer 2017 & &
\end{tabular}

Tabel 9, menunjukan bahwa 18 orang pengolah gula aren mampu memproduksi 425 buah dalam sekali produksi, dengan total penerimaan Rp.3.310.000. Produksi gula aren yang dihasilkan oleh beberapa pengolah hanya sedikit dikarenakan nira aren yang mereka olah juga hanya sedikit.

Berdasakan hasil penelitian, di Dusun kalatin mempunyai 2 orang pengumpul/pembeli gula aren, Gula aren yang dibeli dengan harga Rp.7.000/buah selain saat ini pasokan gula aren banyak dipasaran, juga karena pengumpul yang satu memberikan bayaran uang dimuka dan nanti akan diperhitungkan secara menicil setelah menjual hasil gula aren. Para pengolah juga tidak merasa mengalami kerugian karena bayaran yang mereka minta dimuka, yaitu tanpa bunga oleh pengumpul dan pengumpul mendapatkan untung yang cukup besar. Pengolah yang gula arennya dibeli dengan harga Rp.9.000/buah dikarenakan mereka tidak meminta bayaran dimuka terlebih dahulu kepada pengumpul yang lain, oleh sebab itu gula yang mereka jual mendapatkan harga yang layak.

\section{Keuntungan Usaha Dan Analisis R/C}

Keuntungan usaha dengan analisis R/C yang merupakan pengurangan antara penerimaan usaha dengan biaya total produksi yang dikeluarkan setiap petani dari tahap persiapan hingga hasil produksi, menunjukkan keberhasilan usaha.

Tabel 10 menunjukan bahwa rata-rata keuntungan yang diperoleh 18 orang pengolah gula aren yaitu Rp.898.098/hari dengan total biaya produksi rata-rata sebesar Rp.2.411.902/hari jika tidak dihitung dengan biaya bahan baku. Namun, jika dihitung dengan biaya bahan baku maka total kerugian dari 18 orang pengolah gula aren yaitu Rp.2.903.902/hari dengan total biaya produksi Rp.6.213.902.

Tabel 10. Rata-Rata Tingkat Keuntungan dan Analisis R/C Dalam Kegiatan Usaha Gula Aren

\begin{tabular}{lcc}
\hline \multicolumn{1}{c}{ Uraian } & $\begin{array}{c}\text { Tidak Dihitung } \\
\text { Biaya Bahan } \\
\text { Baku (Rp) }\end{array}$ & $\begin{array}{c}\text { Dihitung Biaya } \\
\text { Bahan Baku } \\
(\mathbf{R p})\end{array}$ \\
\hline Total Penerimaan & 3.310 .000 & 3.310 .000 \\
\hline Biaya Produksi & & \\
-Penyusutan Alat & 46.188 & 46.188 \\
-Bahan Baku & - & 3.802 .000 \\
-Trasnportasi & 180.000 & 180.000 \\
- Tenaga Kerja dk & 1.800 .000 & 1.800 .000 \\
-Tenaga Kerja lk & 385.714 & 385.714 \\
\hline Total Biaya produksi & 2.411 .902 & 6.213 .902 \\
\hline Keuntungan Usaha & 898.098 & -2.903 .902 \\
\hline R/C & 1,37 & 0,53 \\
\hline
\end{tabular}

Sumber : Diolah dari data primer 2017

Analisis keuntungan tersebut kemudian dilanjutkan dengan analisis $\mathrm{R} / \mathrm{C}$ yaitu untuk mengetahui apakah kegiatan usaha pengolahan gula aren mengalami kerugian, impas atau untung. Analisis ini dilakukan dengan membagi antara total penerimaan dan total biaya produksi, jika R/C < 1 (kurang dari satu) maka usaha tersebut rugi, jika $\mathrm{R} / \mathrm{C}=1$ maka pengolah untung tetapi sedikit, sedangkan jika R/C > 1 (lebih dari satu) maka usaha gula aren 
mengalami keuntungan. Dapat dilihat bahwa dalam usaha gula aren jika biaya bahan baku dihitung maka nilai $\mathrm{R} / \mathrm{C}=0,53$ maka usaha gula aren mengalami kerugian. Jika biaya bahan baku tidak dihitung maka nilai $\mathrm{R} / \mathrm{C}=1,37$ maka usaha gula aren mengalami keuntungnan meskipun hanya sedikit.

\section{KESIMPULAN DAN SARAN}

\section{Kesimpulan}

1. Total penerimaan seluruh pengolah gula aren di Dusun Kalatin, sebesar Rp.3.310.000/hari. Dari jumlah penerimaan yang diperoleh seluruh pengolah gula aren dengan biaya yang dikeluarkan sebesar Rp.2.411.902 maka, diperoleh keuntungan oleh 18 orang pengolah yaitu Rp.898.098/hari jika tidak dihitung biaya bahan baku, maka setiap pengolah memperoleh keuntungan Rp.49.898/hari. Namun, jika dihitung biaya bahan baku maka kerugian yang dialami oleh seluruh pengolah gula aren yaitu sebesar Rp.-2.903.902/hari dengan biaya yang dikeluarkan yaitu Rp.6.213.902 dan setiap pengolah mengalami kerugian sebesar Rp.161.327/hari.

2. Pengolahan gula aren di Dusun Kalatin jika hitung biaya bahan baku, tenaga kerja dalam keluarga, tenaga kerja luar keluarga dan transportasi maka otomatis pengolah mengalami kerugian secara ekonomi ditunjukkan oleh nilai $\mathrm{R} / \mathrm{C}=1,37$.

\section{Saran}

1. Untuk meningkatkan pendapatan, sebaiknya para pengolah gula aren tidak terlebih dahulu meminta bayaran dimuka kepada pengumpul pembeli agar pembeli tidak membeli gula dengan harga yang murah. Bagi pengolah yang jumlah gulanya sudah cukup banyak sebaiknya mecari informasi harga pasaran gula aren kepada pembeli baik dari pasar yang ada di desa maupun pasar yang ada dikota. Agar gula aren yang dihasilkan mendapat harga yang layak dan terlebih pengolah juga bisa mendapat banyak langganan.
2. Sebaiknya perlu ada tindakan pemeliharaan pohon aren yang sudah ada khususnya bagi para pengolah gula aren agar, karena air nira yang digunakan 'saguer' merupakan bahan utama untuk mengolah gula aren.

\section{DAFTAR PUSTAKA}

Akuba. 1993. Prospek pengembangan aren di Irian Jaya. Laporan Bulanan. Oktober 1993. Balitka Manado.

Akuba R.H. 2004. Profil Aren. Pengembangan Tanaman Aren. Prosiding Seminar Nasional Aren. Tondano. Balai Penelitian Tanaman Kelapa dan Palma Lain. 9 Juni. hlm.1-9.

Alam S dan D Baco. 2004. Peluang Pengembangan dan Pemanfaatan Tanaman Aren di Sulawesi Selatan. Pengembangan Tanaman Aren. Prosiding Seminar Nasional Aren. Tondano. Balai Penelitian Tanaman Kelapa dan Palma Lain, 9 Juni hlm.1521.

Badan Litbang Pertanian. 2007. Prospek dan Arah Pengembangan Agribisnis: Tinjauan Aspek Kesesuaian Lahan. Badan Litbang Penelitian dan Pengembangan Pertanian, Jakarta. 30 hlm.

Balitka. 1992. Prospek tanaman kelapa, aren, lontar dan gewang untuk menghasilkan gula. Media Komunikasi Penelitian dan Pengembangan Tanaman Industri 1992: 37-40.

Ditjen Perkebunan. 2004. Perkembangan aren di Indonesia. Prosiding Seminar Nasional Aren. Tondano, 9 Juni 2004. Balai Penelitian Tanaman Kelapa dan Palma Lain. hlm. 138-144. 
Effendi, D.S. 2009. Aren, Sumber Energi Alternatif. Warta Penelitian dan Pengembangan Pertanian.Tahun 2009. 31(2):1-3.

Effendi, D. S. 2010.Prospek pengembangan tanaman aren (Arenga pinnata Merr) mendukung kebutuhan bioetanol di Indonesia. Perspektif 9 (1):36 46.

Kusnandar, T. Mardikanto dan A. Wibowo, 2010. Manajemen Agroindustri,Kajian Teori dan Model Kelembagaan Skala Kecil Pedesaan. Cetakan 1.Surakarta. UNS Press.

Lolowang T.F. 2012. Rancangan bangun model pengembangan klaster agroindustri aren di Sulawesi Utara. Disertasi Sekolah Pasca Sarjana, Institutu Pertanian Bogor, Tidak Publikasi.

Lubis W, Sihombing L, Salmiah. 2008. Analisis Nilai Tambah Usaha Pengolahan Gula Aren di Desa Suka Maju Kecamatan Sibolangit Kabupaten Deli Serdang. Program Studi Agribisnis Fakultas Pertanian Universitas Sumatera Utara.

Maskar dan R.B. Maliangkay. 1992. Pengolahan gula merah aren di Desa Wanga Sulawesi Utara. Bulentin Palma, (16):61-64

Maskar dan I.G.P. Sarashuta. 2004. Potensi dan masalah pengembangan tanamanaren di Sulawesi Tengah. Prosiding seminar nasional Aren.

Mubyarto, 1991. "Pengantar Ekonomi Pertanian”, LP3ES. Jakarta.

Mubyarto, 2001. "Ekonomi Pertanian ". Penerbit Gramedia Utama. Jakarta.

Novrianto, H., M.A. Tulalo, B. Rindengan. 2001. Keragaman hasil nira dan gula beberapa kultivar kelapa. Bulentin Balitka 27:7 - 13 .
Patong, S.H. 2003.“Sendi-Sendi Pokok Ilmu Usahatani".Penerbit Gramedia Utama. Jakarta.

Pengembangan Aren untuk 46 Volume 9 Nomor 1, Juni 2010 : 36 - 46 Bioetanol Skala Industri dan UMKM, Hotel Salak Bogor 21 Januari 2010. hlm.17. Tampake, H dan E.

Rindengan, B., S. Karouw dan P. Pasang. 2006. Pengaruh sabut kelapa terhadap kualitas nira aren dan palm wine. J. Penelitian Tanaman Industri, 12(4):166-171.

Rindengan, B dan E.Manaroinsong. 2009. Aren. Tanaman Perkebunan Penghasil Bahan Bakar Nabati (BBM). Pusat penelitian dan Pengembangan Perkebunan. hlm.1-22.

Rompas, S. 2016. "Kelayakan Usaha Gula Aren Di Kawasan Pendukung Kotamobagu Studi Kasus Desa Poopo Kecamatan Passi Timur". Jurusan Sosial Ekonomi Fakultas Pertanian. Unsrat Manado.

Rumokoi, M.M.M. 2004. Aren, Kelapa dan Lontar sebagai Alternatif Pemenuhan Kebutuhan Gula Nasional. Prosiding Seminar Nasional Aren. Balai Penelitian Tanaman Kelapa dan Palma Lain (Balitka)Puslitbangbun Litbang Pertanian. Hal 22-39.

Shafira K, Fauzia L, Iskandarini. 2011. "Analisis Kelayakan Usaha Gula Aren Studi Kasus Desa Mancang Sumatera Utara". Program Studi Agribisnis Fakultas Pertanian Sumatera Utara.

Saleh MS. 2004. Pematahan dormansi benih aren secara fisik pada berbagai lama ekstraksi buah. Agrosains 6 (2): 78-83.

Sarjono. 1986. Pengembangan peralatan untuk pengembangan serbuk gula merah. BBP2IHP. Bogor.

Sarnowo, 2014."Pengantar ilmu ekonomi mikro". Penerbit CAPS (Center For Akademic Publishing Service) Keynesian Baru, Edisi 1. PT Raja Grafindo, Jakarta. 
Soeharno, T.S, 2006. "Teori lokasi industri".Universitas Trisakti Jakarta. Jurnal Acta Diurna Volume III.No.4.Tahun 2014.

Soekartawi, 1995. "Analisis Usahatani”. Universitas Indonesia. Jakarta.

Syakir dan D.S. Effendi. 2010. Prospek Pengembangan Tanaman Aren (Arenga pinnata MERR) untuk Bioetanol, Peluang dan Tantangan. Makalah disajikan dalam Workshop Peluang, Tantangan dan Prospek.

Ulaan, L. S. 2010. Pengaruh Perbandingan Jenis Gula Aren (Arenga Pinnata Merr) Terhadap Mutu Sensoris Halua Kacang Tanah (Arachis hypogeae L) Jurusan Teknik Pertanian Fakultas Pertanian. Unsrat Manado.
Wardiana. 1994. Studi karakter Aren di kabupaten Cianjur Jawa Barat. Buletin Balitka.Balai Penelitian Kelapa Manado. hlm.53-57.

Widyawati N, Tohari P, Yudono, Soemardi I. 2009.Permeabilitas dan perkecambahan benih aren (Arenga pinnata (Wurmb.)Merr.). Jurnal Agronomi Indonesia 37 (2): 152-158.

Wua, S. 2009. "Kajian Usaha Agroindustri Berbahan Baku Nira Aren (CapTikus Dan Gula Aren) Di Desa Tokia Kecamatan Motoling Timur".Jurusan Sosial Ekonomi Fakultas Pertanian. Unsrat Manado.

Yusria, Wa Ode dan Kurniansi Sitti. 2011. "Analisis dan Pendapatan Pengolahan Gula Aren Di Desa Tolowe Ponre Kecamatan Wolo Kabupaten Kolaka".Jurusan Agribisnis Fakultas Pertanian UHO. 